\title{
Barriers and Supports Needed to Improve ET Career Development: A Two-Year View of D.E.E.P. Engineering Technology Career Formation Progress and Impacts
}

\section{Dr. Kristin Kelly Frady, Clemson University}

Kristin Frady is an Assistant Professor at Clemson University jointly appointed between the Educational and Organizational Leadership Development and Engineering and Science Education Departments. Her research focuses on innovations in workforce and career development in educational, community, and industry contexts, specifically focusing on middle skills, STEM, and community college applications.

\section{Prof. Claretha Hughes Ph.D., University of Arkansas, Fayetteville}

Dr. Claretha Hughes is Professor of Human Resource and Workforce Development at the University of Arkansas (UA. Her research interests include valuing people and technology in the workplace, technology development, diversity intelligence, learning technologies, and ethical and legal issues. She has published numerous articles and chapters in peer-reviewed journals, books, and conferences and has 13 books. She serves as a book proposal reviewer for SAGE, Emerald, IGI Global, Palgrave Macmillan, and CyberTech Publishing. She is currently involved in a National Science Foundation Research in Formation of Engineers project as a Co-PI. She has served in manufacturing leadership roles for Coca-Cola Bottling Company Consolidated, Abbott Laboratories, and Burlington Industries. She is a national member of ATD and has twice presented at the ATD International Conference and Exposition. Dr. Hughes is a Langevin Certified Master Trainer, Harvard Management Development Fellow, and a Darden School of Business Minority Executive Education Scholar. She has a PhD in Career and Technical Education from Virginia Tech, Master of Textiles in Textile Technology Management from NC State University, B.A. in Chemistry from Clemson University, and MBA in Management from University of Arkansas.

\section{Dr. Karen A. High, Clemson University}

Dr. Karen High holds an academic appointment in the Engineering Science and Education Department (ESED) at Clemson University. Prior to this Dr. Karen was at Oklahoma State University where she was a professor for 24 years in Chemical Engineering. She received her B.S. in chemical engineering from University of Michigan in 1985 and her M.S. in 1988 and Ph.D. in 1991 in chemical engineering both from Pennsylvania State University. Dr. Karen's educational research emphasis includes faculty development and mentoring, graduate student development, critical thinking and communication skills, enhancing mathematical student success in Calculus (including Impact of COVID-19), and promoting women in STEM. Her technical research focuses on sustainable chemical process design, computer aided design, and multicriteria decision making. She also has extensive experience in K-12 STEM education and program evaluation and assessment. She has held a variety of administrative positions: 1) Director of STEM Faculty Development Initiatives-Clemson, 2) Associate Dean for Undergraduate Studies in the College of Engineering, Computing and Applied Sciences-Clemson, 3) Interim Director of Student Services-Oklahoma State University, 4) Coordinator of the Women in Engineering Program-Oklahoma State University, and 5) Director of the Oklahoma State University Measurement and Control Engineering Center-Oklahoma State University. 


\section{Barriers and Supports Needed to Improve ET Career Development: A Two-Year View of D.E.E.P. Engineering Technology Career Formation Progress and Impacts}

The purpose of the Research in the Formation of Engineers National Science Foundation funded project, Developing Engineering Experiences and Pathways in Engineering Technology Career Formation (D.E.E.P. Engineering Technology Career Formation), is to develop a greater understanding of the professional identity, institutional culture, and formation of engineer technicians and technologists (ET) who are prepared at two-year colleges. ET professionals are important hands-on members of engineering teams who have specialized knowledge of components and engineering systems. Little research on career development and the role of ET in the workforce has been conducted prompting national organizations such as NSF and the National Academy of Sciences to prompt more research in this area [1].

The primary objectives of this project are to: (a) identify dimensions of career orientations and anchors at various stages of professional preparation and map to ET career pathways, (b) develop an empirical framework, incorporating individual career anchors and effect of institutional culture, for understanding ET professional formation, and (c) develop and pilot interventions aimed at transforming engineering formation systems in ET contexts. The three interdisciplinary theoretical frameworks integrated to guide design and analysis of this research study are social cognitive career theory (SCCT) [2], Schein's career anchors which focuses on individual career orientation [3], and the Hughes value framework focused on the organization [4]. SCCT links self-efficacy beliefs, outcome expectations, and personal goals to educational and career decisions and outcomes. SCCT also ties the individual career anchors to the institutional context of the Hughes framework [2].

Initial analyses have revealed gaps and needed areas of support for ET students in the area of professional formation. Thus far, the identified gaps are in institutional policy (i.e. lack of articulation agreements), needed faculty professional development (i.e. two-year faculty on specific career development and professional ET formation needs and four-year faculty on unique needs of transfer students), missing curriculum and resources supporting career development and professional formation of ET students, and integration of transfer student services focusing on connecting faculty and advisors across both institutional levels and types of programs. Significant gaps in the research promoting understanding of the role of ET and unique professional formation needs of these students were also confirmed.

This project has been successful at helping to broaden participation in ET engineering education through integrating new participants into activities (new four-year institutional stakeholders, new industry partners, new faculty and staff directly and indirectly working with ET students) and through promoting disciplinary (engineering education and ET) and cross disciplinary collaborations (human resource development, higher education leadership, and student affairs). With one year remaining before completion of this project, this project has promoted a better understanding of student and faculty barriers supporting career development for ET students and identified need for career development resources and curriculum in ET. 


\section{References}

[1] National Academy of Engineering, "Engineering technology education in the United States," Washington, DC: The National Academies Press, 2016.

[2] R. Lent, and S. Brown, "Social cognitive approach to career development: An overview." Career Development Quarterly, vol. 44, pp. 310-321, 1996.

[3] E. Schein, "Career anchors revisited: Implications for career development in the 21st century," Academy of Management Executive, vol. 10, no. 4, pp. 80-88, 1996.

[4] C. Hughes, "Conceptualizing the five values of people and technology development: Implications for human resource management and development," Workforce Education Forum, vol. 37, no. 1, 23-44, Spring, 2014. 